Scientific paper

\title{
An Assessment of a New Synthetic Procedure for Core-shell Polymeric Supports Based on the Amberlite XAD-4 Adsorbent
}

\author{
Piotr Cyganowski, ${ }^{1}$ * Dorota Jermakowicz-Bartkowiak ${ }^{1}$ \\ and Jacek Chęcmanowski \\ ${ }^{1}$ Division of Polymer and Carbonacenous Materials \\ ${ }^{2}$ Department of Surface Engineering, Catalysis and Corrosion \\ Faculty of Chemistry Wroclaw University of Technology Wybrzeze Wyspianskiego 27 50-370 Wroclaw Poland \\ * Corresponding author: E-mail: piotr.cyganowski@ pwredu.pl \\ phone: +48713202383
}

Received: 23-12-2014

\begin{abstract}
In pursuit for new reactive materials designed for synthesis of functional resins, the novel core-shell type polymeric supports with accessible chloromethyl groups were synthesized. The commercial Amberlite XAD-4 adsorbent was impregnated with different mixtures of vinylbenzylchloride and divinylbenzene, that were further polymerized in the structure of the polymer carrier. The syntheses have been evaluated by recording FT-IR spectra, capturing SEM micrographs as well as analyzing the sorption and desorption of nitrogen at $77 \mathrm{~K}$. The amount of the introduced functionalities has been estimated by chlorine content determination.

Based on the obtained results, the reactive chloromethyl groups were successfully introduced into XAD-4 structure. Captured SEM micrographs revealed that VBC/DVB copolymer has covered initial polymeric matrix of XAD-4 adsorbent. Based on the results we have determined conditions of the synthesis that allow us to receive that effect.
\end{abstract}

Keywords: VBC, DVB, centrifugation, chloromethyl groups, IPN

\section{Introduction}

The most popular supports for preparation ofion-exchange resins are various types of polystyrene $(\mathrm{S})$ and divinylbenzene (DVB) copolymers. A preparation of that type of materials requires in a first step, copolymerization of styrene (S) and divinylbenzene (DVB) to form a crosslinked suspension copolymer, S/DVB. The method allows to obtain a material with transverse, very durable covalent bonds resulting with polymeric beads that are resistant for any kind of chemical environment. ${ }^{1}$ Usually, the copolymerization process is followed by introduction of reactive sites (chloromethyl groups) into polymer structure using bis-chloromethyl ether (BCME) as an alkylating agent. ${ }^{2}$

The procedure has its disadvantages, including extent of methylene binding (reaction of a chloromethylated ring with a benzene ring) which occurs during chloromethylation, influencing the final properties of the S/DVB resins. ${ }^{3}$ Furthermore the strongly carcinogenic character of the BCME creates a pressing need for creating materials that could be equivalent to chloromethylated S/DVB copolymers. ${ }^{4}$

One of the opportunities was created by Subramonian, who proposed the use of vinylbenzyl chloride (VBC) as a starting monomer instead of styrene. ${ }^{3}$ Copolymerization of VBC with DVB results with obtaining a copolymer (VBC/DVB) with chloromethyl groups already existing in the copolymer, ready for direct functionalization to ion exchangers. ${ }^{5,6}$

However, the active sites, derived from VBC, differ with an accessibility in and out polymer matrix. ${ }^{7}$ The phenomenon creates a risk of wasting those precious functionalities during a modification.

In the worldwide literature some methods of improving the accessibility to the reactive chloromethyl groups are reported. The conventional method, ${ }^{8}$ involving the ad- 
dition of the functional monomer (VBC) simultaneously to the supporting monomers $\mathrm{S}$ and DVB, leads to the possibility of this relatively expensive active-site functional monomer being occluded inside the polymer network, and as result, could be not available for reaction. ${ }^{8,9}$ Furthermore, other, more effective methods, as preparation of macroporous materials with large pores, ${ }^{10}$ and appliance of surface-gradient polymerization using VBC as a functional monomer are not fully successful. ${ }^{9}$

The objective of the present studies is an evaluation of the new method of improving access to chloromethyl groups originating from the VBC in a course of synthesis of interpenetrating polymer networks (IPN).

The term interpenetrating polymer networks describes a material containing at least two polymers, each in network form wherein at least one of the polymers is synthesized in presence of the other polymer network. The polymer networks are physically entangled with each other and, in some embodiments, may be also covalently bonded. IPN's have been subject of few monographs, ${ }^{12,13}$ furthermore examples of different materials based on different IPNs are provided for instance in patents' sources. ${ }^{14-16}$ Nevertheless the worldwide scientific and patent literature does not provide information about IPN's, based on the commercial adsorbent and the VBC/DVB copolymer, that were used for functional resins preparation.

The aim of the present work is an evaluation of a procedure of synthesis of new polymeric supports designed for synthesis of new functional resins. IPN's based on the Amberlite XAD-4 adsorbent (macroporous S/DVB copolymer) and the VBC/DVB copolymer have been obtained using impregnation and in subsequent step suspension polymerization technique. The present studies describe the different procedures of synthesis, that lead to obtainment of matrices characterized by improved accessibility to their functionalities. The effectiveness of the presented process has been confirmed by analysis of Fourier's Transformation Infrared Spectra (FTIR). The change in the appearance of the beads of the initial XAD-4 matrix was determined using Scanning Electron Microscopy (SEM). Amount of the chloromethyl groups, introduced into XAD-4 sorbent has been estimated by chlorine content analysis. The accessibility of the reactive chloromethyl groups has been evaluated in course of determination of the changes in the porous structure of the initial polymeric supports.

\section{Materials and Methods}

\section{1. Reagents}

The monomers (VBC, DVB) for the polymerization procedure have been purchased from Sigma-Aldrich Co. The vinylbenzyl chloride (VBC) 99\% (mixture of 3 and 4 isomers) and divinylbenzene (DVB) $80 \%$ were purified before use by the most convenient method-distillation under reduced pressure. Polymer support, the Amberlite XAD-4, and polyvinyl alcohol (PVA, $\mathrm{M}_{\mathrm{W}}=130000$ ) acquired in Fluka have been used as received.

\section{2. Polymerization Procedure}

The IPN resins coded as 1T, 2T, 1TD and 2TD based on the Amberlite XAD-4 adsorbent and the VBC/DVB copolymer have been synthesized using the suspension polymerization technique.

Starting monomers, VBC and DVB (10 mol\% in respect to $\mathrm{VBC}$ ), have been placed in a glass vial. Then, organic solvent, toluene (solution $\mathrm{T}$ ) or mixture of toluene and dodecyl alcohol (solution TD) was added in order to obtain a solution where monomers (VBC and DVB) constitute $65 \mathrm{wt} \%$ (solution T) or $45 \%$ (solution TD). The azobisisobutylonitrile (AIBN, $0.2 \mathrm{wt} \%$ in respect to monomers) was used as the initiator. As the result of appliance the "sol" toluene (in respect to monomers, solution T) it has been expected that VBC/DVB polymer network introduced into the XAD-4 polymer network should reveal expanded-gel structure (resins $1 \mathrm{~T}$ and 2T). ${ }^{17}$ Mixture of the "sol" toluene and "nonsol" dodecyl alcohol should result with porous structure of the introduced VBC/DVB network (solution TD, resins 1TD, 2TD). ${ }^{18}$

The Amberlite XAD-4 adsorbent was being swollen in the selected mixture for 18 hours at $+3{ }^{\circ} \mathrm{C}$ in order to prevent initiation of the polymerization. After that, the impregnated XAD-4 resin has been separated from the excess of the organic phase by centrifugation.

The impregnated XAD-4 supports have been suspended in an aqueous phase composed of polyvinyl alcohol (PVA) and calcium chloride $\mathrm{CaCl}_{2}$. The mixtures have been stirred (300 RPM) under reflux condenser at $55^{\circ}-90$ ${ }^{\circ} \mathrm{C}$ in a tubular reactor equipped with a propeller stirrer. Details of the proceeded synthesis processes are displayed in Table 1.

Table 1. Conditions of the core-shell IPNs' synthesis

\begin{tabular}{|c|c|c|c|c|c|}
\hline \multirow{2}{*}{ Resin } & \multirow{2}{*}{$\begin{array}{l}\text { Impregnating } \\
\text { Solution }^{1}\end{array}$} & \multirow{2}{*}{$\begin{array}{l}\text { Excess of the impregnating } \\
\text { solutions removal }{ }^{2}\end{array}$} & \multicolumn{2}{|c|}{ Centrifugation } & \multirow{2}{*}{$\begin{array}{c}\text { Synthesis } \\
\text { Water phase }^{3}\end{array}$} \\
\hline & & & Speed [RPM] & Time $[\mathrm{s}]$ & \\
\hline$\overline{1 T}$ & $\mathrm{~T}$ & $\mathrm{C}$ & 1000 & 30 & $\mathrm{P}$ \\
\hline $2 \mathrm{~T}$ & & & 500 & 30 & \\
\hline $1 \mathrm{TD}$ & $\mathrm{TD}$ & $\mathrm{C}$ & 1000 & 30 & $\mathrm{P}$ \\
\hline $2 \mathrm{TD}$ & & & 500 & 30 & \\
\hline
\end{tabular}

\footnotetext{
${ }^{1} \mathrm{~T}$-toluene $\mathrm{T}$; TD-mixture of toluene and dodecyl alkohol ${ }^{2} \mathrm{C}$-centrifugation ${ }^{3} \mathrm{P}-\mathrm{PVA}+\mathrm{CaCl}_{2}$
} 
The synthesized IPNs' beads, after polymerization process, have been transferred into fritted-glass funnel and extensively washed with acetone, cold distilled water and hot distilled water, respectively. Then the new coreshell type IPNs were swollen in acetone, dried and extracted in toluene in order to remove all of the unreacted monomers and oligomers. After described procedure the beads of the resins have been dried and used for further procedure.

\section{3. Analysis Methods}

The Fourier's Transformation Infrared Spectroscopy (FTIR) analyses were proceeded to confirm presence of the introduced relativities. The FTIR spectra in $\mathrm{KBr}$ pallets were recorded with use of Perkin-Elmer System 2000 spectrophotometer.

Chlorine content analysis was executed to estimate an amount of the reactive chloromethyl groups introduced into XAD-4 structure. About $30 \mathrm{mg}$ of the dry polymer sample was burned-out in an oxygen-filled flask. The products of burning were adsorbed in diluted hydrogen peroxide solution. The content of $\mathrm{Cl}$ was determined using the Schöniger's method applied to polymers. ${ }^{19}$

Changes in the morphology of the Amberlite XAD4 resin, after polymerization process were examined by scanning electron microscope JSM 5800LV (SEM). Size of the pores and surface area were received using technique of nitrogen adsorption at the liquid nitrogen temperature using Micromeritics ASAP 2020 analyzer. Resultant data were subjected to Brauner-Emmet-Teller (BET) treatment.

\section{Results and Discussion}

The described polymerization procedure was assessed by evaluation of chlorine content, presence of the reactive chloromethyl groups and appearance of the obtained IPNs. The presented results concerns successful syntheses that allowed for determining conditions of the processes.

\section{1. Polymerization}

The main drawback, that has been met during applied polymerization processes, was a proper reagents dispersion. Because of the reagents nature (application of the commercial polymeric sorbents) it has been assumed, that a proper water-phase applied for suspension polymerization procedure should reveal density that allow to suspend the impregnated XAD- 4 beads.

During first attempts of present process designing, as a water phase the mixture of lightly cross-linked polyvinyl alcohol and gelatin was used as a water phase. It was expected that density of the applied mixture will help creating a correct suspension. Instead, the reaction proceeded with a proper reagents dispersion up to $70^{\circ} \mathrm{C}$. After crossing that temperature (up to $90{ }^{\circ} \mathrm{C}$ ) the system revealed agglomeration of the impregnated XAD-4 beads and after synthesis process content of the tubular reactor revealed heterogeneity: next to the IPNs other type of copolymer, probably VBC/DVB, has been obtained. Therefore the samples obtained using that procedure were excluded for further analyses.

Basing on the experience of the authors with the VBC monomer, ${ }^{6,20}$ the water phase composed of PVA and $\mathrm{CaCl}_{2}$ has been prepared and applied to the present processes. As the result, a proper reagents dispersion during synthesis processes was achieved and the obtained products revealed homogeinity. The Figure 1 shows wrong reagents dispersion (a) after appliance of the mixture of the lightly-crosslinked PVA and gelatin as the water phase and the effect of usage of the mixture of PVA and $\mathrm{CaCl}_{2}$ (b)
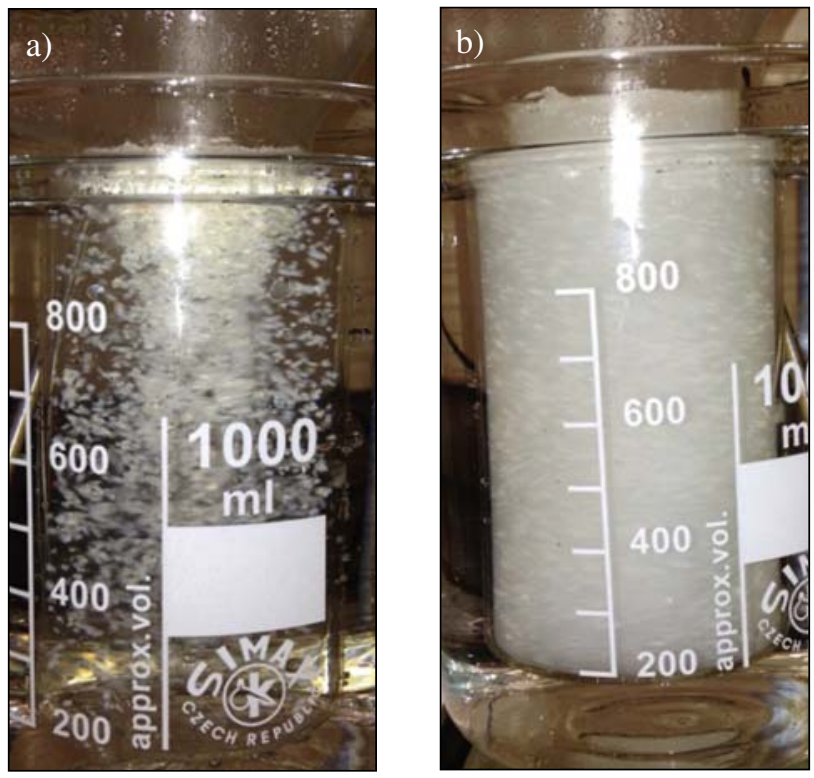

Figure 1. (a) Dispersion of the reagents after applying mixtrure of PVA and gelatin as a suspension agent. (b) Effect of usage of mixture of PVA and $\mathrm{CaCl}_{2}{ }^{22}$

The determined composition of the most suitable water phase allowed to focus on the other aspects of the synthesis. Therefore the processes were diversified using different impregnating solutions ( $\mathrm{T}$ and TD).

\section{2. The synthesis Process Assessment}

The objective of the proceeded polymerization processes was introducing the reactive chloromethyl groups into the Amberlite XAD-4 polymer supports. The procedure could be an alternative for processes of chloromethylation of S/DVB copolymers or usage of VBC/DVB co- 
polymers. Therefore, the presence of the chloromethyl functionalities was the main factor that indicated if the synthesis was successful. For that reason the FT-IR spectra, displayed in the Figure 2, were captured and analyzed.

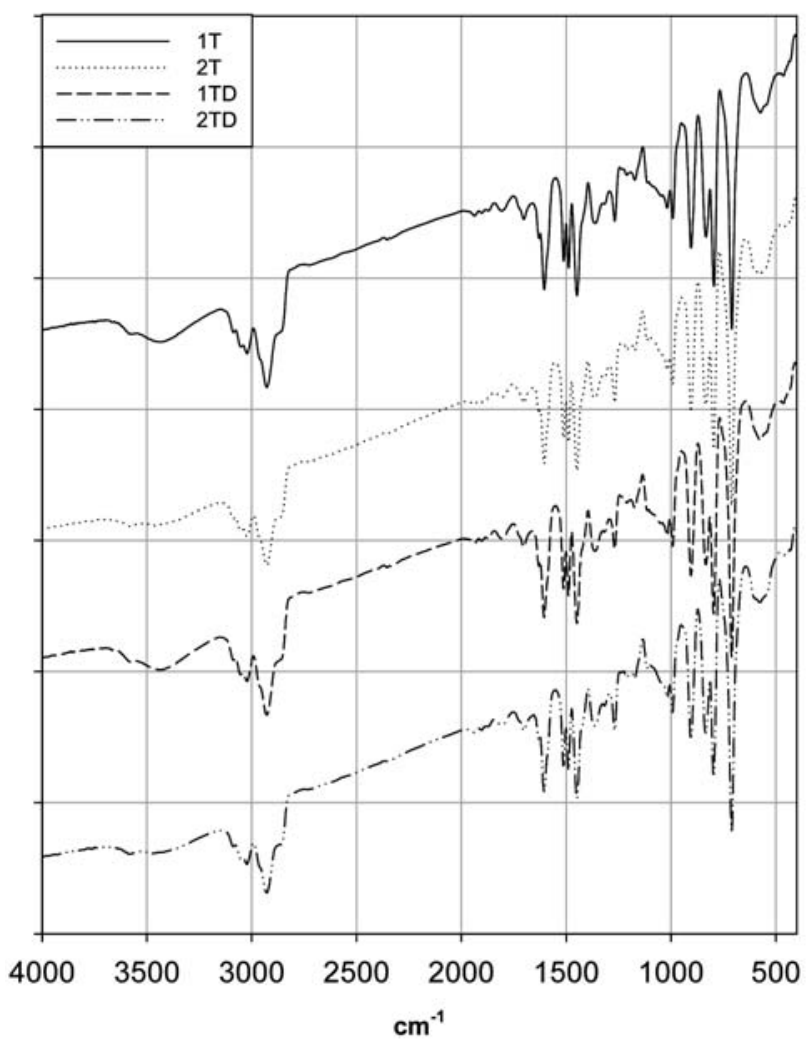

Figure 2. Recorded FT-IR spectra of the resins 1T, 2T, 1TD and 2TD

The spectra of all of the resins reveal sharp peaks at $1268 \mathrm{~cm}^{-1}$ (Figure 2, 1T, 2T, 1TD, 2TD, Figure 2). Those bands have been previously recognized as an indicator of the $\mathrm{C}-\mathrm{H}$ interactions, where $\mathrm{C}$ is simultaneously attached to $\mathrm{Cl}^{6,21}$ The conclusion is supported by appearance of the strong peaks at $709 \mathrm{~cm}^{-1}$ (Figure 2) that could be assigned to the $\mathrm{C}-\mathrm{Cl}$ bonds. Based on the FT-IR spectra it could be stated that the reactive chloromethyl groups were successfully introduced into XAD-4 matrix. The spectra recorded for the resins 1T and 1TD (Figure 2) reveal wide bands at $3438 \mathrm{~cm}^{-1}$ and $3441 \mathrm{~cm}^{-1}$, respectively. Those peaks might be attributed to the presence of the $-\mathrm{OH}$ groups. Appearance of those moieties is probably caused by hydrolysis of the VBC monomer to a vinylbenzyl alcohol. According to Subramonian undesired hydrolysis of the VBC monomer during synthesis process is very difficult to avoid. Nevertheless, presence of the hydroxyl groups is determined only in case of the resins obtained using mixture of monomers in toluene (solution T). There is possibility that the concentration of monomers (65 wt\%) in the used impregnating solution $\mathrm{T}$ (resins $1 \mathrm{~T}$ and $2 \mathrm{~T}$ ) could propagate transformation of the VBC to vinylbenzyl alcohol. Basing on the recorded spectra (Figure 2) hydrolysis of the VBC during synthesis of the resins $2 \mathrm{~T}$ and $2 \mathrm{TD}$ cannot be clearly excluded, but, if occurred, it proceeded to a much lesser extent.

The present studies focus on the selection of an appropriate impregnating solution and method of removal of an excess of it, that was crucial. Insufficient procedure resulted with "over-polymerization", where next to the IPN beads other products were visible. On the other hand too efficient removal could lead to IPNs with reduced amount of the chloromethyl groups introduced in. The presented IPNs are selected ones, which syntheses proceeded successfully and efficiently allowing for direct comparison and selection of suitable techniques.

Determination of the chlorine content at this stage of the synthesis provided an information about the amount of the chloromethyl groups introduced into polymeric precursor simultaneously indicating an efficiency of the process. Presence of the chlorine in the XAD-4 beads could lead to conclusion, that VBC/DVB copolymer has been successfully created inside applied polymer supports. Table 2 displays determined chlorine content in the obtained polymers.

Table 2. Determined amount of chlorine present in the synthesized resins.

\begin{tabular}{cc}
\hline IPN & $\mathrm{Cl}^{1}$ \\
$1 \mathrm{~T}$ & 0.90 \\
$2 \mathrm{~T}$ & 1.41 \\
$1 \mathrm{TD}$ & 0.78 \\
$2 \mathrm{TD}$ & 1.36 \\
\hline
\end{tabular}

${ }^{1}$ Chlorine content $\left[\mathrm{mmol} \cdot \mathrm{g}^{-1}\right]$

The results confirm that the greater centrifugation speed is (see Table 1), the less chlorine content is observed (Table 2, resins 1T, 1TD versus 2T, 2TD). The greatest amount of the chloromethyl groups introduced into XAD-4 matrix using different impregnating solutions has been found for resin $2 \mathrm{~T}(1.41 \mathrm{mmol} / \mathrm{g}$, Table 2$)$. The effect is probably attributed to the intensity of removal of mixture of monomers (centrifugation speed 500 RPM) as well as the combined concentration of the VBC and DVB in the solution $\mathrm{T}(65 \mathrm{wt} \%)$. The conclusion is supported by chlorine content determined for the resins $1 \mathrm{~T}$ and $2 \mathrm{~T}$ (Table 2). The processes were differed by applying different intensity of the removal of an excess of the monomers as well as their concentration applied. Regardless to the used impregnating solution, the centrifugation method turned out to be sufficient. The synthesized inside the XAD-4 matrix VBC/DVB copolymer has not been creating a separate phase, and no additional products were observed. 
The FT-IR studies delivered the proof that the chloromethyl groups have been successfully introduced into XAD-4 polymer supports. The chlorine content indicates correlation between intensity of organic phase removal and amount of chloromethyl groups present in the IPNs' structures. Although those analyses do not provide an insight in the nature of the changes in the morphology of the resins' beads regarding to the applied impregnating solution. Determination of those, could make easier to plan possible applications of the synthesized materials. Therefore SEM micrographs of the obtained resins have been captured.

Figure 3 displays SEM images of the Amberlite XAD-4 adsorbent and the synthesized core-shell type resins. Appearance of the surface of the IPN polymeric supports provides a significant information about nature of the different synthesis processes. Comparison of the structure of the precursor (XAD-4) and derived from it resins 1T and 1TD reveals no change in the morphology of the beads of the resins. Micrographs 1T and 1TD show a smooth porous surface of the polymeric supports. The effect means that no additional network (VBC/DVB) was created outside the XAD-4 grain. Nevertheless, the chlorine content and recorded FT-IR spectra (Table 1, Figure 2, respectively) indicate, that the chloromethyl groups were successfully introduced into precursor. That fact may lead to the conclusion that VBC/DVB copolymer was created inside the porous structure of the Amberlite XAD-4.
An opposite situation is observed in case of the resins 1TD and 2TD (Figure 3), where less intensive centrifugation probably promoted the creation of the VBC/DVB copolymer on the external surface of the initial adsorbent. That means, that reactive chloromethyl groups derived from the VBC monomer may be concentrated inside (the resins 1T, 1TD) as well as on the outside (the resins $2 \mathrm{~T}$, 2TD) of the structure of the Amberlite. The phenomenon is strictly correlated with centrifugation speed (1000 versus 500 RPM). Also, comparing the structures of the resins $2 \mathrm{~T}$ and $2 \mathrm{TD}$ there is a possibility that appliance of the "sol" and "nonsol" organic solvents in the reagents mixture (the solution TD) allowed to obtain material, which pores could be accessible despite presence of the regular VBC/DVB "coating". Taking into account the treatment of the synthesized resins (extensive washing and swelling in acetone and toluene), and the fact, that the beads remained coated regularly (the resin 2TD) or irregularly (the re$\sin 2 \mathrm{~T}$ ), there is a possibility, that those two phases (Amberlite XAD-4 and VBC/DVB) are at least partially interlaced on the molecular scale. Therefore the morphology of the surfaces of the resins (Figure 3) suggest that the result of the synthesis depends on the applied centrifugation speed as well as the composition of the impregnating solutions. Moreover, there is a possibility, that if the surface of the XAD-4 is covered with a layer of the VBC/DVB copolymer, internal surface, interior of the porous architecture, could be also coated with VBC/DVB.
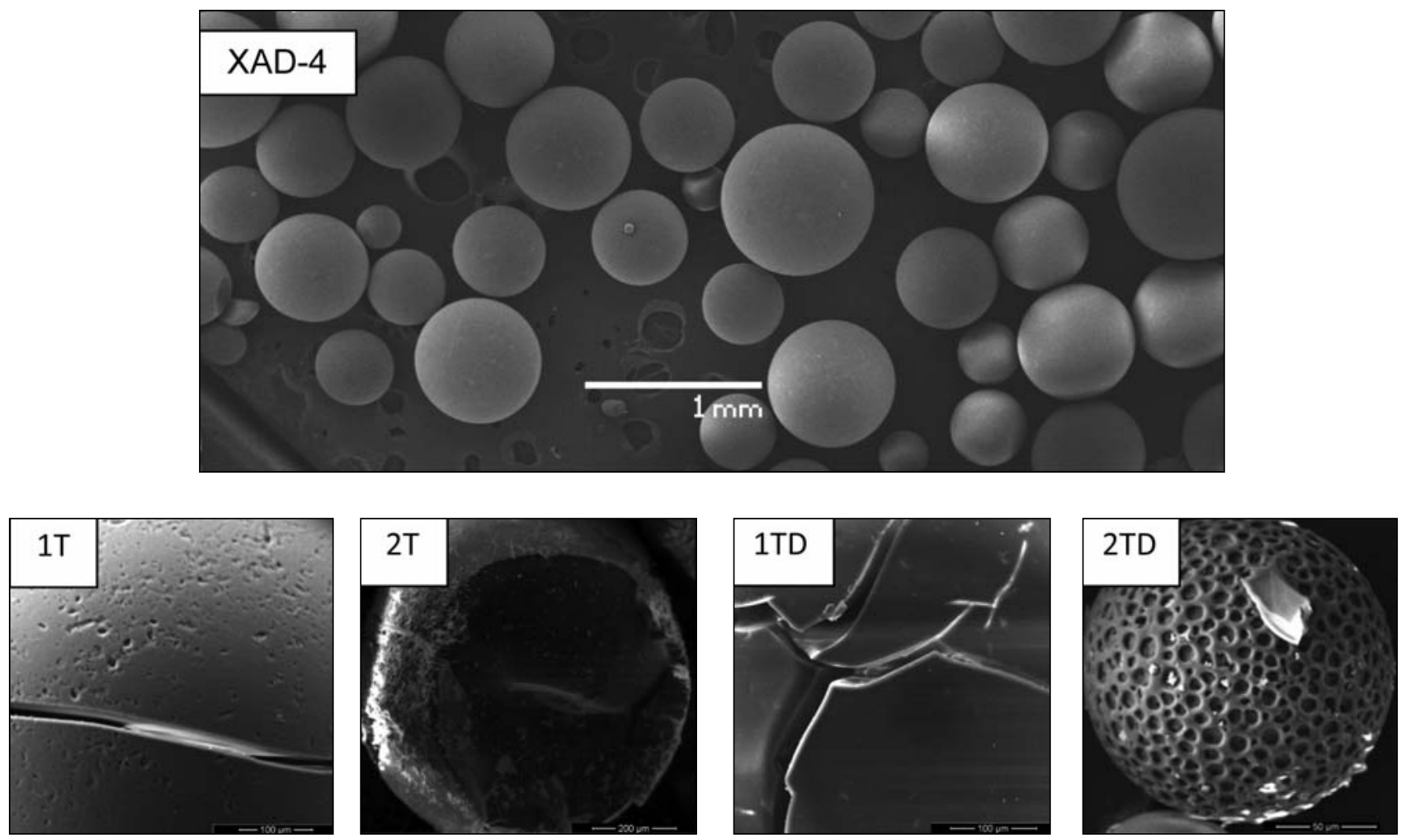

Figure 3. Captured SEM micrographs of the Amberlite XAD-4 adsorbent, and the resins 1T, 2T, 1TD, 2TD. ${ }^{22}$ 
In order to verify that suspicion it was necessary to analyze nitrogen adsorption-desorption isotherms that provide an information about changes of the porous architecture resulted from synthesis of the new materials. The Table 3 presents parameters for the selected resins

Table 3. Basic parameters of the porous structure calculated for the XAD-4 matrix and the resins $2 \mathrm{~T}$ and $2 \mathrm{TD}$.

\begin{tabular}{cccc}
\hline Sample & $\begin{array}{c}\text { BET }^{\mathbf{1}} \\
{\left[\mathbf{m}^{\mathbf{2}} \cdot \mathbf{g}^{\mathbf{- 1}}\right]}\end{array}$ & $\begin{array}{c}\text { Pore volume } \\
{\left[\mathbf{c m}^{\mathbf{3}} \cdot \mathbf{g}^{\mathbf{- 1}}\right]}\end{array}$ & $\begin{array}{c}\text { Average pore } \\
\text { size }[\mathbf{n m}]\end{array}$ \\
\hline XAD-4 & $824 \pm 8$ & 0.91 & 4.41 \\
2T & $452 \pm 9$ & 0.40 & 4.03 \\
2TD & $484 \pm 6$ & 0.57 & 4.26 \\
\hline
\end{tabular}

${ }^{1}$ BET Brauner-Emmet-Teller surface area

Based on the obtained results, the porous structure of the initial polymeric matrix (XAD-4) decreased almost twice as the result of the synthesis processes (Table 3). The same phenomenon may be observed in case of the calculated volume of the pores. However, the estimated average pore size decreased only slightly as the result of the synthesis.

The BET surface, received for the resin 2T and 2TD is comparable, although, the polymeric support, obtained using impregnating solution composed from mixture of monomers in toluene (solution $\mathrm{T}$ ) reveal slightly lower surface area as well as volume of the pores comparing to the resin $2 \mathrm{TD}$. That phenomenon may indicate, that appliance of the solution TD (mixture of the monomers in toluene and dodecyl alkohol) might indeed result with porous structure of the VBC/DVB copolymer introduced into XAD-4 adsorbent.

According to the IUPAC nomenclature the average pore size of approximately $4 \mathrm{~nm}$, places the initial matrix and the obtained resins in area of mesoporous materials. Modification of XAD-4 did not influence average pore size significantly, only slight decrease was observed. That effect, simultaneously with decreasing volume of the pores as well as their surface may suggest, that the VBC/DVB copolymer could cover not only the external surface of the initial matrix (revealed in the Figure 3). In fact, in very simplistic terms, it is possible that the pores could be covered with a thin layer of the introduced copolymer. As the result, there is a possibility that the reactive chloromethyl groups, derived from VBC monomer may be entirely accessible for modification.

\section{Conclusion}

We have synthesized and investigated a series of new polymeric supports with reactive chloromethyl groups using diversified mixtures of the VBC and DVB monomers as well as organic solvents.
The resins covered with a layer of chloromethyl groups (derived from VBC monomer) may be obtained by applying centrifugation of 500 RPM and mixture of toluene and dodecyl alcohol as impregnating solution. Furthermore, based on the analysis of nitrogen sorption and desorption it is possible that the introduced relativities are concentrated also on the internal surface of the polymeric carrier, making them accessible.

\section{Acknowledgement}

This work was financed by a statutory activity subsidy from the Polish Ministry of Science and Higher Education for the Faculty of Chemistry of Wroclaw University of Technology.

\section{References}

1. F. Helfferich, in: Ion Exchange, General Publishing Company, Toronto, 1995.

2. M. Concha-Barrientos, D. I. Nelson, et al., 2004, 2, 16521801.

3. S. Subramonian, React. Funct. Polym. 1996, 29, 129-133. http://dx.doi.org/10.1016/1381-5148(96)00003-X

4. M. Concha-Barrientos, D.I. Nelson, et al., in: Selected occupational risk factors in Comparative quantification of health risk, World Health Organisation, Geneva, 2004.

5. N.D. Harris, Process for preparing chloromethylated polystyrene-divinylbenzene copolymer, US Patent Number 3,872,067, date of patent March 18, 1975.

6. P. Cyganowski, D. Jermakowicz-Bartkowiak, Sep. Sci. Technol. 2014, 49, 1689-1699. http://dx.doi.org/10.1080/01496395.2014.906460

7. R.L. Albright, React. Pol. 1986, 4, 155.

8. T. Balakrishnan, W.T. Ford, J. Appl. Polym. Sci. 1982, 27, 133-138. http://dx.doi.org/10.1002/app.1982.070270115

9. T. Balakrishnan, E. Murugan, J. Appl. Polym. Sci. 2002, 41, 347-364. http://dx.doi.org/10.1002/pola. 10562

10. A. Revillon, A. Guyot, et al., React. Pol. 1989, 10, 11-25. http://dx.doi.org/10.1016/0923-1137(89)90004-3

11. in: Committee on Microwave Processing of Materials: An Emerging Industrial Technology, Microwave Processing of Materials, National Academy Press, 1994.

12. C.H. Sperling, in: Interpenetrating polymer networks and related materials, Plenum Press, New York, 1981. http://dx.doi.org/10.1007/978-1-4684-3830-7

13. D. Klempner, K.C. Rrisch, in: Advances in interpenetrating polymer networks, Technomic Publishing Co. Inc., Basel, 1990.

14. J.H. Barrett, T.J. Howell, et al., 1983, US 4419245 A.

15. L. Feistel, G. Schade, et al., 2005, US 6924317 B6924312.

16. W.I. Harris, 1986, US 4564644 A.

17. D. Jermakowicz-Bartkowiak, B.N. Kolarz, Eur. Polym. J. 2002, 38, 2239-2246.

http://dx.doi.org/10.1016/S0014-3057(02)00129-5 
18. M. Wojaczynska, B.N. Kolarz, J. Appl. Polym. Sci. 1995, 56, 433-439. http://dx.doi.org/10.1002/app.1995.070560404

19. A.I. Vogel, in: Handbook of Quantitative Inorganic Analysis, Longman, London, 1978.

20. D. Jermakowicz-Bartkowiak, React. Funct. Polym. 2005, 65 , 135-142.

http://dx.doi.org/10.1016/j.reactfunctpolym.2004.11.010
21. B. Stuart, in: Infrared Spectroscopy-Fundamentals and Applications, John Wiley \& Sons, Ltd., Chichester, 2004. http://dx.doi.org/10.1002/0470011149

22. P. Cyganowski, D. Jermakowicz-Bartkowiak, etal., Chinese J. Chem. 2015, 33, 594-600

\section{Povzetek}

V raziskavah priprave novih reaktivnih materialov, namenjenih za sintezo funkcionalnih nosilcev, smo sintetizirali nove tako imenovane »core - shell « polimerne nosilce z dostopnimi klorometilnimi skupinami. Komercialni Amberlite XAD - 4 adsorbent smo impregnirali z različnimi mešanicami vinilbenzil klorida in divinilbenzena, ki sta nadalje polimerizirala v strukturi polimernega nosilca. Za karakterizacijo tako pripravljenih nosilcev smo uporabili infrardečo spektroskopijo (FT-IR), SEM mikroskopijo ter analizo absorpcije in desorpcije dušika pri 77 K. Funkcionalizacijsko sposobnost smo ocenili z določitvijo vsebnosti klora.

Na osnovi dobljenih rezultatov lahko zaključimo, da smo reaktivne klorometilne skupine uspešno uvedli v XAD - 4 strukturo. SEM posnetki so pokazali, da je VBC/DVB kopolimer pokril začetno polimerno osnovo XAD-4 adsorbenta. Določili smo reakcijske pogoje, s katerimi je efekt pokritja dosežen. 